\title{
AS DIRETRIZES CURRICULARES NACIONAIS PARA A EDUCAÇÃO. DAS RELAÇÕES ÉTNICO-RACIAIS E A FORMAÇÃO DOCENTE NO CURSO DE HISTÓRIA DA UNIVERSIDADE FEDERAL DO PARÁ
}

\author{
Elton Luis da Silva Júnior ${ }^{1}$ \\ Raquel Amorim dos Santos ${ }^{2}$ \\ Ana Paula Vieira e Souza
}

\begin{abstract}
RESUMO
Esse estudo analisa as Diretrizes Curriculares Nacionais para a Educação das Relações Étnico-Raciais - DCNERE e o processo de formação de professores de História ${ }^{4}$ da Universidade Federal do Pará, Campus Bragança. O estudo apresenta uma abordagem qualitativa com aplicação da pesquisa documental (Projeto Pedagógico do Curso de História). Por meio do PPC do Curso de História o presente trabalho investiga como os Núcleos de Disciplinas do Curso de História contemplam as relações étnico-raciais no Ensino de História. Os resultados revelam que os conteúdos referentes às relações étnico-raciais estão inseridas minimamente no currículo em que forma o professor de História e, de certa maneira, cumpre a exigência formal na legislação. Concluímos que o espaço reservado à Europa ainda é privilegiado por meio do saber historiográfico como o fio condutor que tece os caminhos da historiografia ocidental, o que dificulta discussões sobre o racismo e suas ramificações no contexto escolar.
\end{abstract}

Palavras-chave: Diretrizes Curriculares. Relações Étnico-Raciais. Formação Docente. Ensino de História.

\begin{abstract}
This study analyzes the National Curricular Guidelines for the Education of Ethnic-Racial Relations DCNERE and the process of teacher education of History, Federal University of Pará, Campus Bragança. The study presents a qualitative approach with the application of documentary research (Pedagogical Project of the History Course). Through the PPC of the Course of History the present work investigates how the Nuclei of Disciplines of the Course of History contemplate the ethnic-racial relations in the Teaching of History. The results reveal that the contents related to ethnic-racial relations are inserted minimally in the curriculum in which the teacher of History and, in a certain way, fulfills the formal requirement in the legislation. We conclude that the space reserved for Europe is still privileged through historiographic knowledge as the guiding thread that weaves the paths of

\footnotetext{
${ }^{1}$ Mestrando do Programa de Pós-Graduação em Linguagens e Saberes na Amazônia, Linha de Pesquisa Educação, Cultura e Sociedade da Universidade Federal do Pará (UFPA), Campus Universitário de Bragança/PA. E-mail: eltonluis@ufpa.br.

${ }^{2}$ Doutora e Mestre em Educação pela Universidade Federal do Pará (UFPA). Professora Adjunta A da UFPA, Campus Universitário de Bragança, Faculdade de Educação. Professora do Programa de Pós-Graduação em Linguagens e Saberes na Amazônia (PPLSA), Linha de Pesquisa: Educação, Cultura e Sociedade. Graduada Plena Pedagogia pela Universidade da Amazônia (UNAMA). Pesquisadora do Núcleo de Estudos e Pesquisa sobre Formação de Professores e Relações Étnico-Raciais (GERA/UFPA). E-mail: rakelamorim@yahoo.com.br

${ }^{3}$ Professora da Universidade Federal do Pará - Campus de Bragança. Doutora e Mestre em Educação na Linha Políticas Públicas Educacionais pela Universidade Federal do Pará (UFPA). Graduada Plena em Secretariado Executivo Bilíngue (UNAMA). Professora do Programa Linguagens e Saberes da Amazônia (PPLSA) na Linha de Educação. Membro do Grupo de Estudos e Pesquisa Trabalho e Educação (GEPTE/UFPA). E-mail: paulladesa@gmail.com

${ }^{4}$ Estes resultados são preliminares, e fazem parte do processo de pesquisa e levantamentos de dados necessários para a elaboração da dissertação de mestrado do Programa de Pós-Graduação em Linguagens e Saberes da Amazônia, orientado pela Profa. Dra. Raquel Amorim dos Santos.
} 
Western historiography, which makes it difficult to discuss racism and its ramifications in the school context.

Keywords: Curricular Guidelines. Ethnic-Racial Relations. Teacher Training. History Teaching.

\section{INTRODUÇÃO}

Este estudo analisa as relações étnico-raciais no Ensino de História da Universidade Federal do Pará, Campus Bragança por meio da análise do Projeto Pedagógico do Curso de História - PPC/FAHIST/UFPA. Através dele, procuramos refletir sobre a importância da formação docente voltada para as relações étnico-raciais. A análise incidirá nos conteúdos apontados pelas DCNRER e as legislações voltadas para a temática étnico-racial, como a Lei Federal $n^{\text {o }} 10.639 / 03^{5}$.

Após 15 anos da promulgação da Lei Federal n 10.639/03, muitos desafios ainda são postos para sua efetiva implementação, dentre eles a dificuldade das Secretarias de Educação em estabelecer mecanismos que transformem o disposto na referida Lei em práticas pedagógicas cotidianas, não apenas com a inclusão de conteúdos, mas sim com a crítica à discriminação de cunho racial que existe na sociedade brasileira, resultado de anos de reinvindicação do Movimento Negro.

As legislações que tratam da temática étnico-racial (Leis nº 10.639/2003, 11.645/2003, Diretrizes Curriculares Nacionais para a Educação das Relações Étnico-Raciais, entre outras) se tornaram obrigatórias nas instituições de ensino no sentido de estabelecer uma ruptura com a memória coletiva de que no Brasil existe uma harmonia racial, uma visão idílica de que todos vivem em iguais condições de oportunidades.

Nesse sentido, este artigo procura fazer uma breve análise do processo de formação de professores de História ${ }^{6}$, da Universidade Federal do Pará, Campus Bragança. O objetivo é analisar em que medida o curso evidencia os pressupostos da legislação, sobretudo, as Diretrizes Curriculares Nacionais para a Educação das Relações Raciais - DCNRER.

\footnotetext{
${ }^{5}$ BRASIL. Lei $\mathrm{n}^{\mathrm{o}}$ 10.639, de 9 de janeiro de 2003. Altera a lei $\mathrm{n}^{\mathrm{o}}$ 9.394, de 20 de dezembro de 1996, que estabelece as diretrizes e bases da educação nacional, para incluir no currículo oficial da rede de ensino a obrigatoriedade da temática "História e Cultura Afro-Brasileira", e de outras providências. Disponível em: http// www.planalto.gov.br/ccilvil_03/leis/2003/110.639.htm. Acesso em: 15 de nov. 2018.

${ }^{6}$ Estes resultados são preliminares, e fazem parte do processo de pesquisa e levantamentos de dados necessários para a elaboração da dissertação de mestrado do Programa de Pós-Graduação em Linguagens e Saberes da Amazônia, orientado pela Profa. Dra. Raquel Amorim dos Santos.
} 


\section{PERCURSO METODOLÓGICO}

O estudo é de abordagem qualitativa por entendermos ser a mais adequada ao objeto de pesquisa. Segundo Lakatos e Marconi (2011) esse tipo de metodologia permiti-nos analisar, interpretar e descrever, de maneira detalhada, dados observados durante o processo de construção da pesquisa.

Utilizamos a pesquisa documental que, de acordo com Ludke e André (1986, p. 38), "[...] busca identificar informações e fatos a partir de hipóteses de interesse". Cellard (2008), por sua vez salienta que uma pesquisa documental deve "[...] constituir um corpus satisfatório e esgotar todas as pistas capazes de lhe oferecer informações interessantes" (CELLARD, 2008, p. 298).

$\mathrm{Na}$ pesquisa documental analisamos o Projeto Pedagógico do Curso de História, especialmente os Núcleos de Disciplinas do Curso de História, Núcleo de Conteúdos Histórico-Historiográficos, Núcleo de Conteúdos Pedagógicos, Núcleo de Estágios e TCC, as habilidades e competências que o futuro docente deve apreender e a ementa das disciplinas relacionadas à diversidade étnico-racial.

Os dados coletados foram analisados por meio de análise de conteúdo (categorial), que segundo Bardin (2011), consiste no desmembramento do texto em categorias agrupadas analogicamente. Dessa forma, na fase da pesquisa documental fizemos primeiramente a préanálise dos documentos (seleção dos documentos, preparação do material para análise); em seguida, a exploração do material (escolha das unidades, enumeração e classificação) e; por fim, o tratamento dos dados, interferência e interpretação (análise de conteúdo).

\section{RESULTADOS E DISCUSSÕES}

\subsection{EDUCAÇÃO PARA AS RELAÇÕES RACIAIS}

O Brasil como uma sociedade multirracial e pluriétnica nos faz refletir sobre a importância de um Ensino de História que preze pela reversão de valores e conceitos centrados em uma perspectiva monocultural ${ }^{7}$. O Ensino de História que era lecionado nas escolas brasileiras, sobretudo na década de 60 do século passado, contemplava apenas "[...] a formação cívica no intuito de ajustar os jovens para os interesses do Estado, pautada no ideal

\footnotetext{
${ }^{7}$ Para Santos (2008), o colonialismo, ao reduzir experiências que existem no mundo, construiu lógicas de hierarquização do saber, que situa a ciência ocidental como única detentora do saber cientifico. Para ele, a perspectiva monocultural aponta para uma história com uma única direção, sobretudo o eurocentrismo, a naturalização das diferenças, que se assenta na classificação da população em categorias que naturalizam hierarquias.
} 
de progresso, tendo como base teórica a historiografia tradicional ${ }^{8}$ positivista e eurocêntrica" (MOREIRA, 2015, p. 38). E, desta forma, muitos grupos sociais não eram vistos como protagonistas da história.

No final dos anos 70, o cenário político brasileiro foi protagonizado por novos atores sociais que entravam em cena por meio dos movimentos populares, principalmente ligados à questão de gênero e etnia, eles reivindicavam uma maior participação e reconhecimento de direitos e cidadania. Fernandes (2005) sustenta que esses movimentos sociais, como o movimento indigenista que reivindicava do Governo Federal a demarcação de terras indígenas e o direito à própria cultura, e os movimentos consciência negra, lutavam contra "[...] quaisquer formas de preconceito e discriminação racial, bem como pelo direito à diferença, pautada no estudo e valorização de aspectos da cultura afro-brasileira" (FERNANDES, 2005, p. 381). Para ele, é neste contexto que a questão da valorização da diversidade étnico-cultural se insere no sistema educacional brasileiro, que sinalizava a introdução de conteúdos sobre a História da África e do negro em nosso país.

Nas considerações de Coelho (2009), a década de 1980 ficou marcada pela evolução do pensamento sobre a educação no Brasil, esse movimento esteve relacionado à ansiedade para dar fim a tudo que pudesse "[...] parecer resquício do pensamento autoritário que marcara o regime militar" (idem, 2009, p.95).

Para Gomes (2010, p.2-3), na década de 80, durante o processo de reabertura política no Brasil, assistimos a "[...] uma nova forma de atuação política dos negros e negras brasileiros [...] passaram a atuar ativamente por meio dos movimentos sociais, sobretudo os de caráter identitário trazendo diversas problematizações nas formas de atuação política". Ainda corrobora que as reinvindicações do Movimento Negro indagavam o Estado, a esquerda brasileira e os movimentos sociais sobre a sua neutralidade de posicionamento diante da centralidade da raça na formação do país.

Na década de 90 é promulgada a nova Lei de Diretrizes e Bases da Educação-LDB (Lei Federal $n^{\circ}$ 9.394/96), na qual diversos artigos fazem referência à valorização da miscigenação cultural, como o Art. $26 \S 4^{\circ}$, ao definir que "[...] o ensino de história do Brasil levará em conta as diferentes culturas e etnias para a formação do povo brasileiro

\footnotetext{
${ }^{8}$ No final do século XIX o historiador mais evidente no ocidente era Leopold Von Ranke, suas obras centravamse no Estado, ou seja, a antiga história política recuperou a predominância (BURKE, 1988). Nesse período histórico os governos europeus passaram a considerar a história como um meio de promover a unidade nacional, de educar para a cidadania, ou meio de fazer propaganda nacionalista (BURKE, 2012). Esse modelo historiográfico se perpetuou por muito tempo refletindo na maneira com que se ensinava a história, centrada apenas em grandes feitos e em grandes personagens da história.
} 
especialmente as matrizes indígenas, africanas e europeias" (BRASIL, 1996, p.9). Portanto, a despeito de ainda não estabelecer a obrigatoriedade do ensino de história e cultura africana e indígena, a LDB já sinalizava que deveriam ser levadas em consideração as três matrizes formadoras da sociedade brasileira.

Após um intenso processo de lutas e reinvindicações do Movimento Negro, em 9 de janeiro de 2003 é promulgada a Lei $\mathrm{n}^{\circ} 10.639 / 03^{9}$ que torna obrigatório o Ensino de História da África e da Cultura Africana e Afro-Brasileira na Educação Básica. Para Coelho e Coelho (2018), mesmo após mais de 15 anos da promulgação da referida lei, aspectos da Cultura afrobrasileira ainda são mostrados em sala de aula como algo incidental, por meio de abordagens festivas que aparecem isoladamente do saber escolar cotidianamente construído. Para eles, esse quadro está relacionado com a maneira pela qual a legislação é percebida, pois em muitos casos o entendimento é de que basta apenas inserir alguns conteúdos relacionados à história africana e afro-brasileira, sem que haja a problematização da visibilidade dada à historiografia europeia no currículo da Educação Básica (COELHO; COELHO, 2018).

Segundo os autores, desde o ano de 2003 houve um aumento dos espaços destinados à História da África e à cultura afro-brasileira nos livros didáticos. Porém, isso não significa que houve uma alteração na perspectiva eurocêntrica acerca da História do Brasil presente naquelas obras "[...] continua soberana a perspectiva eurocêntrica, segundo a qual a história confunde-se com a trajetória europeia, a qual intervém e significa a trajetória brasileira" (COELHO e COELHO, 2018, p.4).

Nas considerações de Munanga (2005) para uma nova perspectiva epistemológica da Cultura Africana e Afro-Brasileira não se trata apenas de substituir uma cultura eurocêntrica por uma cultura afrocêntrica, mas sim reconhecer os diversos caminhos culturais que se encontram e desencontram em processos históricos que se (re)modelam no tempo e no espaço.

\footnotetext{
${ }^{9}$ A lei 10.639 é aprovada em 1999, mas promulgada apenas em 9 de janeiro de 2003 e gera mudanças na L.D.B, em seus artigos 26-A, 79-A e 79-B:

Art. $1^{\underline{0}}$ A Lei n⿳ำ 9.394, de 20 de dezembro de 1996, passa a vigorar acrescida dos seguintes arts. 26-A, 79-A e 79-B:

Art. 26-A. Nos estabelecimentos de ensino fundamental e médio, oficiais e particulares, torna-se obrigatório o ensino sobre História e Cultura Afro-Brasileira.

$\S 1$ O O conteúdo programático a que se refere o caput deste artigo incluirá o estudo da História da África e dos Africanos, a luta dos negros no Brasil, a cultura negra brasileira e o negro na formação da sociedade nacional, resgatando a contribuição do povo negro nas áreas social, econômica e política pertinentes à História do Brasil. $\S 2^{0}$ Os conteúdos referentes à História e Cultura Afro-Brasileira serão ministrados no âmbito de todo o currículo escolar, em especial nas áreas de Educação Artística e de Literatura e História Brasileiras.

Art. 79-A. (VETADO).

Art. 79-B. O calendário escolar incluirá o dia 20 de novembro como 'Dia Nacional da Consciência Negra'.
} 
Ante as resistências e dificuldades encontradas para colocar em prática o disposto na Lei $n^{\circ} 10.639 / 2003$, bem como a necessidade de normas complementares para os sistemas de ensino que orientassem os profissionais da educação no sentido de estabelecer caminhos para a maneira de ser trabalhada a questão étnico-racial no âmbito escolar, o Conselho Nacional de Educação - CNE aprovou a Resolução 1 de 17/04/2004, que institui as Diretrizes Curriculares Nacionais para o Ensino das Relações Étnico-Raciais - DCNRER.

Nas considerações de Santos (2009, p. 151):

[...] a partir desse momento as escolas de Educação Básica no Brasil passam a ter um documento oficial que discute e aprofunda o conteúdo da Lei Federal $\mathrm{n}^{\mathrm{o}}$ 10.639/2003, capaz de orientar a prática pedagógica como forma de divulgar positivamente a cultura afro-brasileira e africana.

A autora analisa que tanto a implementação da Lei Federal $n^{\circ} 10.639 / 2003$ e das DCNRER vêm acrescentar as "[...] demandas que o Movimento Negro reivindicavam, bem como de intelectuais e de outros movimentos sociais na luta pela superação do racismo e da discriminação racial existente na sociedade brasileira" (idem, 2009, p. 151).

As DCNRER se constituem de um conjunto de orientações e princípios que vislumbram políticas de reparações, de valorização e de ações afirmativas de nossa cultura afro para o projeto de educação no Brasil (SANTOS, 2009).

Na concepção de Santos (2009, p. 151):

Art. $2^{\circ}$ As Diretrizes Curriculares Nacionais para a Educação das Relações ÉtnicoRaciais e para o Ensino de História e Cultura Afro-Brasileira e Africanas constituem-se de orientações, princípios e fundamentos para o planejamento, execução e avaliação da Educação, e têm por meta promover a educação de cidadãos atuantes e conscientes no seio da sociedade multicultural e pluriétnica do Brasil, buscando relações étnico-sociais positivas, rumo à construção de nação democrática.

Concordamos com Santos (2009, p. 152) quando afirma que "[...] as DCNRER também apresentam como objetivo maior a formação para a cidadania e o exercício de uma consciência democrática na sociedade brasileira". Essa afirmativa corrobora com a assertiva de Coelho e Coelho (2018) quando afirmam que o Parecer aprovado pelo Conselho Nacional de Educação - CNE aponta que a "[...] inclusão de conteúdos não é o objetivo final da legislação" (COELHO; COELHO, 2018, p. 4).

Segundo o Parecer CNE/CP 3/2004 no sentido de evidenciar as políticas de reconhecimento, valorização e reparação, estas legislações buscam a "[...] divulgação e produção de conhecimentos, bem como de atitudes, posturas e valores que eduquem os cidadãos quanto à pluralidade étnico-racial" (BRASIL, 2004, p. 1). Nas considerações de Coelho e Coelho (2018) " [...] o fim último da política educacional é a inclusão de temas e 
princípios contrários às perspectivas demarcadas e informadas pelo racismo" (COELHO, COELHO, 2018, p. 4), ou seja, as DCNRER visam proporcionar processos que valorizem, reparem e reconheçam a Cultura Africana e Afro-Brasileira.

As DCNRER ainda asseguram que:

$\S 2^{\circ} \mathrm{O}$ Ensino de História e Cultura Afro-Brasileira e Africana tem por objetivo o reconhecimento e valorização da identidade, história e cultura dos afro-brasileiros, bem como a garantia de reconhecimento e igualdade de valorização das raízes africanas da nação brasileira, ao lado das indígenas, europeias, asiáticas.

Percebemos que no discurso das DCNRER há uma tentativa de romper com o silêncio, práticas xenófobas, discriminatórias e preconceituosas além de romper também com uma "cultura negra invisível [...] como bem evidencia a historiografia oficial brasileira [...]" (SANTOS, 2009, p. 152). Para Coelho e Coelho (2008, p. 4) "[...] está claro que a memória histórica brasileira é informada por um viés racista, especialmente demonstrada no mito da democracia racial".

Há a necessidade de firmar uma história africana marcada não pela subalternidade ou inferioridade, mas sim pelo seu protagonismo em todos os setores da vida social. A escola como uma instituição social não pode mais dissimular a inexistência da Cultura AfroBrasileira e Africana em seu cotidiano, como mostra a história da educação no Brasil. Reconhecer e valorizar a identidade, história e cultura do povo negro requer uma nova postura no cerne da sociedade que perpassa pela visibilidade do patrimônio histórico e cultural afrobrasileiro, além de mudança no discurso, na postura e no modo de tratar a população negra, busca-se com isso "[...] desconstruir o mito da democracia racial presente na sociedade brasileira" (SANTOS, 2009, p. 152).

As DCNRER em seu Art. $3^{\circ}$ estabelecem que a educação para as relações raciais “[...] será desenvolvida por meio de conteúdos, competências, atitudes e valores, a serem estabelecidos pelas Instituições de Ensino e seus professores com o apoio e supervisão dos sistemas de ensino, entidades mantenedoras e coordenações pedagógicas" (BRASIL, 2004, p.32). Percebe-se que as DCNRER estabelecem certa autonomia aos professores e à escola no sentido de construir e respeitar uma identidade e memória coletiva que prezem por uma reconstrução epistemológica da História e Cultura Afro-Brasileira e Africana na Educação Básica.

A despeito de a Lei Federal $\mathrm{n}^{\mathrm{o}} 10.639 / 03$ estabelecer preferencialmente os componentes curriculares de Educação Artística, Literatura e História do Brasil no que tange o estudo da História e Cultura Africana e Afro-brasileira, não excluem das outras áreas do 
conhecimento edificar uma nova forma de analisar a diversidade cultural e humana presente na sociedade brasileira. Para que o disposto nestas legislações se concretize em práticas pedagógicas de ensino é necessária uma "[...] mobilização por parte dos agentes sociais que fazem parte da escola, em particular os professores que lidam de forma direta com os conteúdos programáticos em sala de aula" (SANTOS, 2009, p. 152).

As DCNRER estabelecem ainda a possibilidade de os sistemas de ensino realizarem parceiras com grupos sociais que discutem sobre a temática étnico-racial, em seu Art. $4^{\circ}$ as DCNRER dispõem que:

Os sistemas de ensino e os estabelecimentos de ensino poderão estabelecer canais de comunicação com grupos do Movimento Negro, grupos culturais negros, instituições formadoras de professores, núcleos de estudos e pesquisas, como os Estudos AfroBrasileiros, com a finalidade de buscar subsídios e trocar experiências para planos institucionais, planos pedagógicos e projetos de ensino.

O discurso presente neste artigo é o de ampliar os recursos disponíveis para fortalecer o conhecimento sobre essa temática que muitas vezes são ocultados dos currículos escolares, dessa forma as escolas podem contar com entidades que são comprometidas com um discurso contra-hegemônico que preze pelo reconhecimento e valorização da História do povo negro.

No sentido de garantir uma educação de qualidade, com professores qualificados e em instituições educacionais com infraestrutura adequada, as DCNRER prescrevem no Art. $5^{\circ}$ :

Os sistemas de ensino tomarão providências no sentido de garantir o direito de alunos afrodescendentes de frequentarem estabelecimentos de ensino de qualidade, que contenham instalações e equipamentos sólidos e atualizados, em cursos ministrados por professores competentes no domínio de conteúdos de ensino e comprometidos com a educação de negros, sendo capazes de corrigir posturas, atitudes, palavras que impliquem desrespeito e discriminação.

As DCNRER não estão preocupadas com a "mera inclusão de conteúdos" (COELHO; COELHO, 2018, p. 5), como muitas vezes é entendida a legislação, mas também “[...] pelo compromisso dos sistemas de ensino em proporcionar a qualidade do ensino tanto em nível de infraestrutura quanto de formação inicial e continuada de professores" (SANTOS, 2009, p. 153). Concordamos com a assertiva de Coelho e Coelho (2018) quando estabelecem a importância de formar docentes capazes de concretizar as diretrizes e promover uma educação que esteja ligada ao respeito, à diferença, à pluralidade étnica, à diversidade cultural, que permaneça voltada à valorização de todo e qualquer grupo humano e que tenha "[...] condições de subverter as estereotipias cristalizadas e disseminadas ao longo da história da educação brasileira" (SANTOS, 2009, p. 154). 
Segundo o Art. $6^{\circ}$ das DCNRER, os casos de discriminação serão examinados e dados os encaminhamentos para a solução de situações de cunho discriminatório pelos Órgãos Colegiados dos estabelecimentos de Ensino.

Os órgãos colegiados dos estabelecimentos de ensino, em suas finalidades, responsabilidades e tarefas, incluirão o previsto exame e encaminhamento de solução para situações de discriminação, buscando-se criar situações educativas para o reconhecimento, valorização e respeito da diversidade.

Para além de um contexto de implementação de legislações que respondem a demandas históricas do Movimento Negro percebemos um momento de redefinição do papel do Estado brasileiro: “[...] não mais o Estado totalmente neutro diante da complexa interrelação de classe, gênero, raça e desigualdade, mas sim como um propulsor de transformações sociais" (GOMES, 2008, p. 81).

As Diretrizes, segundo Gomes (2008) evidenciam elementos de reflexão sobre qual deve ser a postura ética a conduzir e nortear ações educativas que possam construir uma postura que nos liberte das amarras do racismo. As DCNRER preocupadas com os estereótipos sobre o povo negro reproduzidos nos livros didáticos, prescreve em seu Art. $7^{\circ}$ que "[...] os sistemas de ensino orientarão e supervisionarão a elaboração e edição de livros e outros materiais didáticos, em atendimento ao disposto no Parecer CNE/CP 003/2004" (BRASIL, 2004, p.11).

Ao analisar as interpretações históricas sobre os negros nos livros didáticos permeadas pelo racismo, discriminação e preconceito, Ribeiro (2013, p. 297) destaca a "[...] ausência de uma análise mais profunda no interior dos próprios textos didáticos de História do Brasil sobre as representações do negro [...] não há o exercício de reflexão sobre como as imagens dos negros são construídas nos livros didáticos de História" (RIBEIRO, 2013, p. 297). Para Santos (2009) isso demonstra a "[...] urgente necessidade de orientação e supervisão na elaboração dos livros didáticos, para que se crie um contexto civilizatório, longe de uma visão minimizada e folclorizada do negro" (SANTOS, 2009, p. 154).

De modo geral, estas documentações oficias estabelecem mais do que as implementações de legislações federais, elas representam "[...] a superação das desigualdades" (GOMES, 2008, p. 80), o Estado Brasileiro começa a problematizar os debates sobre a garantia de direitos que incluísse a diversidade como fundamental no combate à discriminação de cunho racial. A autora destaca ainda que outro aspecto é a possibilidade de uma mudança de perspectiva sobre a História da África e do negro brasileiro ao inserirmos 
uma discussão com dimensões sociais e culturais extrapolando assim a dimensão monocultural/eurocêntrica que permeia a Historiografia brasileira.

$\mathrm{Na}$ assertiva de Santos (2009):

[...] educação antirracista que se pretende no âmbito da escola e da sociedade deverá atentar para a educação das relações étnico-raciais. Isso quer dizer que a discussão acerca da África e a cultura afro-brasileira e africana somente terão sentido na práxis pedagógica se for realizada num contexto de uma postura étnica como norteadora do processo educativo. Essa postura não se constrói no segregacionismo, mas na relação do eu e do outro, com vista a tornar as relações na escola emancipatórias (SANTOS, 2009, p. 155).

Para Gomes (2008) é no campo da liberdade que a questão racial deve ser pensada, a esse respeito assegura:

[...] a educação para as relações étnico-raciais que cumpre o seu papel é aquela em que as crianças, os adolescentes, os jovens e os adultos negros e brancos, ao passarem pela escola básica, questionem a si mesmos nos seus próprios preconceitos, tornem-se dispostos a mudar posturas e práticas discriminatórias, reconheçam a beleza e a riqueza das diferenças e compreendam como essas foram transformadas em desigualdades e relações de poder e de dominação (GOMES, 2008, p.83).

A educação antirracista se constitui a partir do reconhecimento e valorização da história e cultura dos afro-brasileiros. É necessário que crianças, jovens, adultos negros e brancos construam posições críticas e de enfrentamento às práticas e posturas discriminatórias que possibilitem perceber as diferenças socioculturais, transformando a maneira como as relações étnico-raciais são percebidas no campo da educação.

Nesse sentido, a Lei 10.639/03 e as DCNRER constituem marcos importantes no que se refere a superação de práticas racistas e desigualdades raciais na educação brasileira, estes mecanismos institucionais vislumbram práticas pedagógicas interculturais com o propósito de contribuir para subversão de práticas racistas e discriminatórias. O contexto destas legislações contribui para que professores e alunos possam realizar diálogos interdisciplinares que possam desmistificar o mito da democracia racial.

Os desafios, os avanços e as possibilidades para a execução, em ações e práticas pedagógicas da Lei 10.639/03 e das DCNRER são frutos de diversas reinvindicações do movimento negro, estas conquistas refletem anseios de respeito à diferença e à valorização cultural de um povo que contribui de maneira importante em diversos momentos históricos da sociedade brasileira.

Segundo Santos (2009, p. 155-156): 
[...] não basta chegar às escolas e ser esquecida nas prateleiras das bibliotecas de nossas instituições de ensino; é necessário discuti-la, entendê-la à luz da história e disseminá-la no Projeto Político Pedagógico, em todas as áreas de conhecimento, nos encontros de pais e educadores. É necessária uma articulação com a comunidade escolar, nas relações comunidade escolar e local, na formação continuada de professores.

A escola como instituição formadora ocupa um lugar de destaque na edificação cultural e social dos alunos e professores, e a discussão sobre a questão racial está inserida em um contexto onde o principal alvo da educação antirracista é a edificação de uma sociedade realmente democrática que reconheça e respeite as diferenças. Nesse sentido, formar professores que tenham a sensibilidade de trabalhar as relações raciais livre de estereótipos e preconceitos se faz necessário em um contexto em que não se pode mais negligenciar ou ocultar as contribuições que a cultura africana e afro-brasileira desempenha como uma das matrizes que edificaram tanto a nossa história, quanto nossa cultura.

A seguir apresentamos a análise do Projeto Político Pedagógico - PPC, do Curso de História da Universidade Federal do Pará, Campus Bragança, para verificarmos se ele cumpre as orientações dispostas nas Diretrizes Curriculares Nacionais para e Educação das Relações Raciais.

\section{O CURSO DE LICENCIATURA EM HISTÓRIA E A FORMAÇÃo DOCENTE PARA AS RELAÇÕES RACIAIS}

Para compreendermos como o curso de Licenciatura em História contempla as DCNRER analisaremos o Projeto Político Pedagógico do Curso de História ${ }^{10}$, do Campus Bragança $^{11}$. Conforme as Orientações para a Educação das Relações Étnico-Raciais “[...] o ponto de partida para a inserção das Diretrizes Étnico-Raciais é o Projeto Político Pedagógico Institucional e dos Cursos [..] das IES" (BRASIL, 2006, p. 132-133).

Para Veiga (2003) os Projetos Políticos Pedagógicos - PPC representam questões normativas que influenciam/interferem no contexto educacional, seja na educação Básica ou em Nível Superior. Para Coelho e Coelho (2018) esse tipo de documentação expressa também o modo como a legislação educacional, voltada para as relações raciais, é praticada. Dessa

\footnotetext{
${ }^{10}$ O PPC do Curso de História foi elaborado por uma Comissão constituída pelos docentes e alguns discentes do Curso de História, no ano de 2012.

${ }^{11}$ O Campus Universitário de Bragança foi criado em 1987 e funcionou primeiramente com os cursos de Geografia, História, Letras, Matemática e Pedagogia. A partir de 1997 foram implantados os cursos de Ciências Biológicas, Ciências Sociais e Licenciatura Plena em Ciências do Ensino Fundamental. Com o objetivo de formar profissionais que atendessem às necessidades da região, a Universidade Federal do Pará criou o Curso de Engenharia de Pesca. Ademais, fortaleceu os cursos existentes, com a contratação de docentes e técnico administrativos, assim como investiu em infraestrutura (PPC, HISTÓRIA, p. 5).
} 
forma, o desenho curricular do PCC pode representar os interesses e aspirações das Instituições que os produzem no que se refere à formação dos educandos ou de futuros profissionais da educação.

No Projeto Político Pedagógico do Curso de História da Universidade Federal do Pará, Campus Bragança, procuramos observar elementos que demonstram o compromisso com a implementação da Lei $n^{\circ}$ 10.639/03 e as Diretrizes Curriculares Nacionais para a Educação das Relações Étnico-Raciais em Núcleos de Disciplinas do Curso de História, como o Núcleo de Conteúdos Histórico-Historiográficos, o Núcleo de Conteúdos Pedagógicos, Núcleo de Estágios e TCC, as habilidades e competências que o futuro docente deve apreender e o ementário das disciplinas relacionadas à diversidade étnico-racial.

A educação para as relações raciais tem como objetivo possibilitar o reconhecimento e a valorização da cultura negra brasileira e africana, contribuindo para a desconstrução da visão eurocêntrica petrificada no imaginário social. Nesse sentido, formar docentes capazes de ministrarem disciplinas que contemplem uma perspectiva positiva do negro na sociedade brasileira como protagonista de nossa história é um desafio e uma necessidade.

Discutir o racismo em suas diversas ramificações é também propiciar uma reeducação para as relações raciais. As DCNRER apontam caminhos e possibilidades para o exercício de novas práticas de formação inicial docente em busca de uma educação multicultural e antirracista. Portanto, é necessário que os cursos de licenciatura contemplem a temática racial de maneira crítica de modo a problematizar a visibilidade histórica dada à cultura europeia nos currículos.

O curso de História tem como objetivo central:

Formar o professor-pesquisador de História [...], na perspectiva de que os egressos possam dominar plenamente os conhecimentos históricos e historiográficos, bem como articular os conteúdos científicos, técnicos e pedagógicos, elementos necessários para sua atuação nas instituições de ensino, ou seja, para a condução do processo de ensino-aprendizagem em História na Educação Básica, junto às séries do ensino fundamental $\left(6^{\circ}\right.$ ao $9^{\circ}$ ano) e do ensino médio $\left(1^{\circ}\right.$ ao $3^{\circ}$ ano $)$ e demais ambientes de trabalho em que este profissional seja requisitado (PPC, HISTÓRIA, 2012, p. 9-10).

No Curso de História, UFPA/Bragança, existe um leque variado de disciplinas de natureza historiográfica, a configuração das disciplinas está ordenada de acordo com a divisão quadripartite da História (História Antiga, Medieval, Moderna e Contemporânea), acrescida de disciplinas que contemplam a História do Brasil, da América e da Região Amazônica.

A partir dessa configuração curricular o PPC demonstra o perfil do professor a ser formado, que deve ter um conhecimento aprofundado do saber historiográfico, do saber de 
referência da História. As disciplinas que apontam para o saber historiográfico estão inseridas no Núcleo de Conteúdos Histórico-Historiográficos, que consiste:

[...] reflexão e análise dos variados períodos e processos históricos, sob diferentes matizes e concepções teórico-metodológicas, definindo e problematizando os grandes recortes espaço-temporais (PPC, HISTÓRIA, 2012, p. 13-14).

Percebemos a predominância do saber historiográfico na formação do egresso. $O$ professor a ser formado deve, portanto, dominar a compreensão de períodos e processos históricos para realizar reflexões e análises a partir de recortes espaço-temporais.

O Núcleo é composto pelas disciplinas obrigatórias, sistematizadas na Tabela I:

TABELA I - Núcleo de Conteúdos Histórico-Historiográficos

\begin{tabular}{|c|l|c|}
\hline Núcleo & \multicolumn{1}{|c|}{ Disciplinas } & Carga Horária \\
\hline & História Antiga I & 68 \\
& História Antiga II & 68 \\
& História Medieval I & 68 \\
& História Medieval II & 68 \\
& História Moderna I & 68 \\
& História Moderna II & 68 \\
& História Contemporânea I & 68 \\
Núcleo de Conteúdos & História Contemporânea II & 68 \\
Histórico/historiográficos & História da América I & 68 \\
& História da América II & 68 \\
& História da África & 51 \\
& História do Brasil I & 68 \\
& História do Brasil II & 68 \\
& História do Brasil III & 68 \\
& História do Brasil IV & 68 \\
& História da Amazônia I & 68 \\
& História da Amazônia II & 68 \\
& História da Amazônia III & 68 \\
& Metodologia de Pesquisa em História & 68 \\
\hline
\end{tabular}

Fonte: Tabela elaborada pelos autores a partir dos dados do PCC/História, nov. 2018.

Nesse Núcleo, a carga horária total é de 1.275 horas/aula, o que corresponde a $43,9 \%$ do total da carga horária do curso. Isso sintetiza a preocupação do curso em formar profissionais que dominem o conhecimento, a produção e o saber historiográfico, o que corrobora com uma das habilidades e competências que o aluno deve ter ao concluir o curso, que é " $[\ldots]$ conhecer e problematizar os diferentes conceitos históricos e historiográficos que auxiliam o historiador na análise e interpretação das estruturas e relações sócio-históricas de uma dada realidade" (PPC, HISTÓRIA, 2012, p. 10).

As disciplinas do Núcleo de Conteúdos Histórico-Historiográficos, conforme a tabela I compõem a maior parte da parcela de carga-horária do curso, ou seja, o lugar central da formação está na discussão acerca dos saberes de referência, o chamado "núcleo duro" do 
curso, outra questão é o espaço estrutural na formação ofertada, evidenciado tanto a História de que está se tratando, como também a perspectiva que é privilegiada no curso durante o processo de formação docente.

Isso pode ser reflexo da apropriação que o curso faz das Diretrizes Curriculares Nacionais para os Cursos de História (PARECER CNE/CES n 492/ 2001), pois essas Diretrizes destacam a importância do domínio de produções historiográficas ao fazer a definição de alguns conteúdos que devem ser priorizados:

\begin{abstract}
Conteúdos históricos/historiográficos e práticas de pesquisa que, sob diferentes matizes e concepções teórico-metodológicas, definem e problematizam os grandes recortes espaço-temporais. Conteúdos que permitam tratamento especializado e maior na verticalidade na abordagem dos temas, resguardadas as especificidades de cada instituição e dos profissionais que nelas atuam [...]. Conteúdos complementares que forneçam instrumentação mínima, permitindo a diferenciação de profissionais da área, tais como: atividades pedagógicas, fundamentos de arquivologia, de museologia, gerenciamento de patrimônio histórico, necessariamente acompanhadas de estágio (PARECER CNE/CES n 492/ 2001, p. 9-9).
\end{abstract}

Os conteúdos históricos e historiográficos assumem nas Diretrizes Curriculares Nacionais para os Cursos de História uma função estrutural, enquanto os outros são considerados complementares do curso, como as disciplinas relacionadas a atividades pedagógicas.

Guimarães (2015) estabelece que no Brasil ainda é recorrente a crença de que em alguns cursos de licenciatura, de História, por exemplo, o professor para ser "bom" precisa "saber a História", ou seja, ele deve ter o domínio do conteúdo historiográfico, no que se refere a períodos e processos históricos. Para ela, os elementos pedagógicos, de formação docente e as experiências cotidianas ainda são vistos como saberes complementares, de segunda ordem, que possuem uma menor importância na hierarquia disciplinar.

A despeito de centrarem a formação nesses conteúdos do saber de referência, o processo de formação docente do curso de história está voltado não somente em construir profissionais que dominem apenas o conhecimento histórico e historiográfico, mas também possibilitar ao futuro docente construir métodos de ensino-aprendizagem que possam proporcionar aos alunos da Educação Básica (Ensino Fundamental e Médio) que aqueles conhecimentos adquiridos na graduação sejam apreendidos pelos discentes dos anos iniciais da Educação Básica Nacional. Nesse sentido, a formação para o exercício da docência encontra-se no Núcleo de Disciplinas Pedagógicas e no Núcleo de Estágios e TCC que articulam História e Educação, conforme tabela abaixo: 
TABELA II - Núcleo de Disciplinas Pedagógicas e no Núcleo de Estágios e TCC

\begin{tabular}{|c|l|c|}
\hline Núcleo & \multicolumn{1}{|c|}{ Disciplinas } & Carga Horária \\
\hline Núcleo de Conteúdos & Psicologia do Ensino Aprendizagem & 68 \\
Pedagógicos & Didática e o Ensino de História & 68 \\
& Metodologia do Ensino de História & 68 \\
& Política Educacional Brasileira & 68 \\
& Seminários de História e Educação & 68 \\
& Seminários de Filosofia e Educação & 68 \\
& LIBRAS & 68 \\
\hline Núcleo de Estágios e & Estágio Supervisionado I & 102 \\
TCC & Estágio Supervisionado II & 102 \\
& Estágio Supervisionado III & 102 \\
& Estágio Supervisionado IV & 102 \\
& Monografia I & 68 \\
& Monografia II & 68 \\
\hline
\end{tabular}

Fonte: Tabela elaborada pelos autores a partir dos dados do PPC, nov. 2018.

Segundo o PPC, o Núcleo de Disciplinas Pedagógicas tem como objetivo “[...] abarcar os conteúdos pedagógicos com o intuito de desenvolver as competências e habilidades necessárias para a ação docente no Ensino de História, em diferentes níveis educacionais" (PPC, HISTÓRIA, 2012, P. 14). Portanto, além de dominar o saber historiográfico, o egresso deve construir mecanismos de práticas docentes que tornem o ensino de História acessível para alunos em situação escolar.

Para Caime (2015) um conhecimento consistente sobre a disciplina História implica em conhecer não apenas a estrutura do conhecimento histórico, mas também na apropriação de conhecimentos pedagógicos que lhes permitam a mobilização de estratégias e recursos que transformem o saber historiográfico em saber para ensinar, ou seja, em saberes válidos socialmente pertinentes às características e finalidades da escola por meio de processos de tornar o saber acadêmico em saber a ensinar.

No Núcleo de Estágios e TCC, o PPC estabelece que essas disciplinas estão voltadas para "[...] atividades curriculares de formação plena do professor-pesquisador, proporcionando situações de prática docente, pesquisa e elaboração de material, além de formação continuada" (idem, 2012, p. 15-16). As atividades curriculares devem orientar a formação do professor para situações em que a prática docente permita refletir sobre questões pedagógicas referentes ao ensino de História.

O demonstrativo das competências e habilidades no Núcleo de Disciplinas Pedagógicas por atividades curriculares são: 
TABELA III - Competências e Habilidades no Núcleo de Disciplinas Pedagógicas

\begin{tabular}{|c|c|c|}
\hline & COMPETÊNCIAS/HABILIDADES & ATIVIDADES CURRICULARES \\
\hline$\square$ & $\begin{array}{l}\text { Compreender a complexidade da atividade docente, } \\
\text { não a dissociando de seus fundamentos político- } \\
\text { pedagógicos e da pesquisa, tanto no âmbito formal } \\
\text { como em práticas não formais de ensino; } \\
\text { Refletir sobre as questões educacionais e } \\
\text { pedagógicas referentes ao ensino da História na } \\
\text { Educação Básica, de forma a propor projetos de } \\
\text { intervenção na realidade escolar, capazes de } \\
\text { permitir a formação histórica do cidadão; } \\
\text { Transitar pelos saberes históricos e pedagógicos } \\
\text { com competência para elaborar material didático } \\
\text { em diversas linguagens, amparados em referências } \\
\text { teórico-metodológicas trabalhadas no curso; } \\
\text { Promover a educação dos alunos no sentido amplo, } \\
\text { incluindo, além do ensino de disciplinas escolares e } \\
\text { o desenvolvimento cognitivo, o cuidado com } \\
\text { aspectos afetivos, físicos, socioculturais e éticos, } \\
\text { sobretudo atuando na formação plena da cidadania; } \\
\text { Compreender e problematizar o conhecimento } \\
\text { pedagógico, sua investigação e prática, de forma } \\
\text { que norteie a sua atuação na Educação Básica. }\end{array}$ & $\begin{array}{l}\text { Seminários de História e Educação } \\
\text { Seminários de Filosofia e Educação } \\
\text { Política Educacional Brasileira } \\
\text { Psicologia do Ensino Aprendizagem } \\
\text { Didática e o Ensino de História } \\
\text { Metodologia do Ensino de História } \\
\text { LIBRAS }\end{array}$ \\
\hline
\end{tabular}

Fonte: Tabela elaborada pelos autores a partir dos dados do PCC, nov. 2018.

A partir destas habilidades e competências percebe-se que para além de formar um pesquisador, existe também a preocupação do Curso de História em formar profissionais comprometidos com a prática docente que tenham " [...] domínio da natureza do conhecimento histórico e das práticas essenciais de sua produção e difusão nos âmbitos acadêmico e escolar [...]" (PPC, HISTÓRIA, 2012, p. 14).

Para Caimi (2015) o processo de ensinar História não está apenas em possuir conhecimentos históricos, é necessário que durante a formação o egresso tenha contato com elementos pedagógicos e/ou conhecer referências de psicologia de aprendizagem. A autora chama a atenção para a necessidade de superar visões reducionistas que defendem a supremacia do saber historiográfico e o domínio do conhecimento histórico na tarefa de se ensinar a História em detrimento dos saberes didático-pedagógicos.

No Núcleo de Estágios e TCC (Tabela IV) as habilidades e competências são: 
TABELA IV - Núcleo de Estágios e TCC

\begin{tabular}{|c|c|c|}
\hline & COMPETÊNCIAS/HABILIDADES & $\begin{array}{c}\text { ATIVIDADES } \\
\text { CURRICULARES }\end{array}$ \\
\hline & $\begin{array}{l}\text { Selecionar e organizar conteúdos de História, de modo a } \\
\text { assegurar sua aprendizagem pelos alunos a partir da } \\
\text { realidade discente, bem como da cultura local; } \\
\text { Selecionar e usar recursos didáticos adequados e } \\
\text { estratégias metodológicas do ensino da História de acordo } \\
\text { com o grau de maturidade pedagógica e psicológica dos } \\
\text { alunos; } \\
\text { Desenvolver métodos e técnicas que favoreçam o } \\
\text { exercício da pesquisa histórica e educacional. }\end{array}$ & $\begin{array}{l}\text { Estágio Supervisionado I } \\
\text { Estágio Supervisionado II } \\
\text { Estágio Supervisionado III } \\
\text { Estágio Supervisionado IV }\end{array}$ \\
\hline
\end{tabular}

Fonte: Tabela elaborada pelos autores a partir dos dados do PCC, nov. 2018

Dentre as habilidade e competências neste núcleo de disciplinas o aluno tem que assegurar o processo de aprendizagem a partir da realidade discente e da cultura local, além de elaborar metodologias em que o Ensino de História esteja de acordo com o nível de maturidade psicológica do aluno. Em ambos os núcleos citados observamos que ensino e pesquisa fazem parte do objetivo final do profissional a ser formado. A esse respeito o PPC corrobora:

[...] o curso forma o profissional de História fundamentando-se no exercício da pesquisa e em sua capacidade de produzir conhecimento [...] e refletir sobre as questões educacionais e pedagógicas referentes ao ensino da História na Educação Básica [...] (PPC, HISTÒRIA, 2012, p.10-11).

Apesar de a pesquisa em História ser também apresentada como um elemento importante para o egresso, entendemos que o percurso curricular do curso sempre procurar entrelaçar o saber historiográfico com elementos de práticas didático-pedagógicas referentes ao ensino de História.

O PPC o Curso de História pretende ainda formar um cidadão crítico e participativo. Assim, assegura:

Considerando os eixos norteadores da Lei de Diretrizes e Bases, o Curso de História apresenta no cerne da constituição curricular, eixos temáticos que envolvem questões fundamentais para a compreensão, debate e transformação social, tais como: cidadania, ética, moral, cultura, dentre outros. (PPC, HISTÓRIA, 2012, p.1011)

Inferimos que neste conteúdo discursivo o PPC traz a possibilidade de serem evidenciados temas outrora excluídos e/ou invisibilizados pela historiografia, como debates 
sobre a história e cultura africana e afro-brasileira que contribuam positivamente para as discussões acerca das relações étnico-raciais.

Em relação à formação para a educação das relações raciais e na perspectiva de construir debates sobre cultura, cidadania, ética e moral, o PCC procura trazer em sua política de inclusão as orientações básicas da Lei 10.639/2003 e das Diretrizes Curriculares para a Educação das Relações Étnico-raciais e para o Ensino de História e Cultura Afro-brasileira e Africana, e, finalmente, da Lei 11.645/2008. Nesse sentido, o PPC afirma:

\begin{abstract}
a) uma ampla discussão das ementas das disciplinas do curso de forma a corresponderem à necessária ênfase e valorização das matrizes culturais africana e indígena, considerando-se que as mesmas não devem ser encapsuladas em disciplinas específicas, como História da África e História Indígena e do Indigenismo, já obrigatórias, mas alterar todo o desenho curricular da graduação em história;

b) a formação de grupos de estudos da história e cultura afro-brasileira e indígena, como o Núcleo de Estudos Afro-brasileiros (NEAB) e/ou o Núcleo de Estudos Afroindígenas (NEAI), que deverão ser núcleos acadêmicos que desenvolvam pesquisas e atividades explicitamente vinculadas aos estudos afro-brasileiros e africanos e indígenas e à educação das relações étnico-raciais (PPC, HISTÓRIA, 2012, p. 4041).
\end{abstract}

Nesse sentido, encontramos no PPC o Núcleo de Conteúdos Específicos, onde está inserida a disciplina sobre Cultura Afro-brasileira e Africana "[...] que permite um tratamento especializado e maior verticalidade na abordagem de temas considerados fundamentais para a formação do professor-pesquisador em História" (PPC, HISTÓRIA, 2012, p.14). Este Núcleo é composto pelas disciplinas obrigatórias: História Indígena e do Indigenismo, História e Cultura Afro-Brasileira e Africana, Historiografia Brasileira, Fundamentos Teóricos e Filosóficos da História I, Fundamentos Teóricos e Filosóficos da História II. Neste caso, nos interessa, para fins de análise, apenas as disciplinas História e Cultura Afro-Brasileira e Africana e Historiografia Brasileira.

A disciplina História e Cultura Afro-Brasileira e Africana possui uma carga horária de 51 horas, consideramos dentro desta perspectiva a disciplina Historiografia Brasileira por ela contemplar as produções historiográficas sobre a sociedade brasileira entre o século XIX e XX, que conta com uma carga horária de 68 horas/aula. Há ainda a disciplina História da África, que está inserida no Núcleo de Conteúdos Histórico-Historiográficos, que possui uma carga horária de 51 horas/aula, a menor do referido Núcleo. Essas disciplinas possuem um total de 171 horas, o que corresponde a 5,85\% da carga horária total do curso de História. Uma carga horária muito pequena, para a quantidade de elementos que norteiam uma educação para as relações raciais. 
A ementa da disciplina Historiografia Brasileira dispõe sobre os elementos:

Historiografia brasileira do século XIX e início do XX. Nação e Civilização: IHGB e a História Nacional. Varnhagen e a história oficial do império. Narrativa crítica e verdade em Capistrano de Abreu. O modernismo e a história da formação da sociedade brasileira: Caio Prado Junior, Gilberto Freire e Sergio Buarque de Holanda.

Apesar de essa disciplina não ser necessariamente voltada para as relações raciais entendemos que por ser uma disciplina que discorre sua perspectiva sobre a historiografia brasileira entre o final do século XIX e início do XX, momento em que diversas teorias raciais começam a ganhar forma na sociedade brasileira, ela pode de alguma maneira estabelecer uma visão que proporcione ao docente em formação perceber os momentos históricos em que a desigualdade racial começa a ganhar força no Brasil, sobretudo, com o mito da democracia racial.

Segundo a ementa da disciplina História da África busca-se evidenciar:

\begin{abstract}
A África nos relatos e na historiografia ocidental. Diversidade da presença humana no ambiente africano desde a chamada pré-história, discutindo as civilizações e sociedades africanas. Representações do mundo, conhecimentos técnicos, práticas culturais. Estudo das sociedades africanas envolvidas e efetivadas pelo tráfico de escravos inaugurado na Idade Moderna. Conformação da Afro-América. Mestiçagem na perspectiva da História Cultural. Estudo e análise das abordagens teóricas e metodológicas encontradas no ensino; dos diversos materiais didáticos e das práticas avaliativas. Prática docente em História. (PPC, HISTÒRIA, 2012, p.73).
\end{abstract}

Já a disciplina História e Cultura Afro-Brasileira e Africana, segundo a ementa, trabalha a questão:

Etnia, cultura e democracia: o Atlântico negro. África e o Brasil africano: as origens africanas da cultura brasileira, suas formas de expressão e as questões que envolvem a sua aceitação. Elaboração de materiais didáticos e pesquisas sobre as culturas africanas e afro-brasileiras. Prática docente em História (PPC, HISTÒRIA, 2012, p. 73).

Se considerarmos apenas as ementas destas disciplinas, podemos supor que elas contemplam de maneira limitada as orientações expressas no Parecer CNE/CP 003/2004 sobre a "[...] demanda da comunidade afro-brasileira por reconhecimento, valorização e afirmação de direitos, no que diz respeito à educação" (BRASIL, 2004, p. 11). A assertiva de Coelho e Coelho (2018) evidencia que é necessário que nos percursos curriculares seja inserida uma crítica subjacente às legislações, sobretudo as que obrigam que aquelas temáticas sejam inseridas nos currículos da Educação Básica e do Ensino Superior. Os autores vão além, ao estabelecer que não é somente adicionar conteúdos que fazem referência a matriz africana, 
mas sim tecer uma crítica à perspectiva eurocêntrica que atentem para outros olhares sobre nossa trajetória histórica.

Pereira (2017) evidencia que existem fragilidades no processo de formação docente no que se refere ao combate ao racismo, para a autora "a demanda pelo ensino de conteúdos específicos - nesse caso o ensino de história e cultura afro-brasileira - requer uma tradução pela ação docente em história, não somente sua introdução no currículo escolar" (PEREIRA, 2017, p. 26).

Para Coelho e Coelho (2018) a formação docente seria uma importante estratégia no processo de implementação das legislações que tratam da temática étnico-racial, no sentido de dominar as habilidades e competências que são necessárias ao combate do racismo em qualquer nível de ensino. Porém, não encontramos descritas no PPC do Curso de História habilidades e competências que o egresso em formação deve ter no que se refere à educação para as relações raciais, como estabelecem as DCNRER.

Quando confrontamos a carga horária total do curso com as disciplinas sobre formação docente e as referentes a educação para as relações étnico- raciais constatamos que ela é insuficiente para conseguir dar conta de uma efetiva educação antirracista, não apenas pela carga horária, mas sim pela ausência de uma crítica voltada à perspectiva eurocêntrica da História

Percebemos, ao analisar o PPC, a invisibilidade desta temática no processo de formação docente, entendemos que é necessário mais que uma introdução instrumentalizada da legislação, a inclusão de disciplinas não deve está presente nos currículos apenas para cumprir formalmente o que está disposto na legislação, mas é necessária uma mudança estrutural no currículo.

De um lado o saber de referência, ou seja, o saber historiográfico dominando a carga horária do Curso de História, visto ainda como o saber que sustenta a formação do docente em história (conforme a Tabela I), essa formação ainda aparece muito atrelada a uma perspectiva em que privilegia a Europa "[...] não só como a matriz que dá inteligibilidade à disciplina, mas que percebe o Velho Continente, senão como o epicentro, como o fator determinante da história vivida em qualquer parte do globo" (COELHO; COELHO, 2018, p.23).

Percebemos a quase total ausência de discussões e orientações das DCNRER para o Ensino de História e Cultura Afro-Brasileira e Africana no Projeto Pedagógico do Curso de História da Universidade Federal do Pará, Campus Bragança. Entendemos que há a necessidade de uma reconfiguração estrutural no PCC de História que dê visibilidade à 
Cultura Africana e Afro-brasileira, não apenas com a inserção de conteúdos, mas sim, problematizando o espaço privilegiado que a historiografia europeia ocupa na tradição disciplinar quadripartite da História.

\section{CONCLUSÃO}

Neste recorte preliminar de análise do PPC do Curso de História, Campus Bragança, constatamos que minimamente alguns conteúdos referentes às relações raciais estão inseridas no currículo em que forma o professor de História. De certa maneira, cumpre com a exigência formal prevista na legislação. No entanto, o espaço reservado à Europa ainda é privilegiado por meio do saber historiográfico como o fio condutor que tece os caminhos da historiografia ocidental. Isso dificulta que discussões sobre o racismo e suas ramificações sejam enfrentadas, pois, a formação inicial não constrói problemáticas no que se refere a perspectivas que desmitifiquem o mito de uma sociedade que vive em harmonia racial.

O professor chega na educação básica sem de fato ter apreendido um conhecimento capaz de contribuir para a desconstrução de preconceitos raciais. Para Coelho e Coelho (2018) o espaço destinado ao enfrentamento do racismo nas escolas é inversamente proporcional ao que as competências necessárias ao exercício da docência ocupam no currículo de formação de professores de História.

Nossa intenção é contribuir para que seja dada visibilidade a uma formação docente que privilegie debates e discussões para uma construção positiva das relações raciais e, dessa forma, romper com um currículo arraigado em uma perspectiva quadripartite da história, fazendo uma crítica à preponderância eurocêntrica que marca o percurso curricular dos professores em formação do Curso de licenciatura em História, Campus Bragança.

\section{REFERÊNCIAS}

CAIME, Flávia Eloisa. O que precisa saber um professor de História? História e Ensino, Londrina, v.21, n.2, p. 105-124, jul./dez. 2015.

CELLARD, A. A análise documental. In: POUPART, J. et al. A pesquisa qualitativa: enfoques epistemológicos e metodológicos. Petrópolis, Vozes, 2008.

COELHO, Wilma de Nazaré Baía. A cor ausente. $2^{\circ}$ ed.- Belo Horizonte: Mazza Edições, 2009. 
COELHO, M. C; COELHO, W. de N.B. As licenciaturas em história e a Lei 10.639/2003: percursos de formação para o trato com a diferença. Educação em Revista. Belo Horizonte. Vol. 34. 2018.

FERNANDES, José Oriá. Ensino de história e diversidade cultural: desafios e possibilidades. Cad. Cedes, Campinas, vol. 25, n. 67, p. 378-388, set./dez. 2005. Disponível em http://www.cedes.unicamp.br. Acesso em: 10 de nov. 2018.

GOMES, N. L. A questão racial na escola: desafios colocados pela implementação da Lei 10.639/03. In: Multiculturalismo: diferenças culturais e práticas pedagógicas. Vozes, 2008.

GOMES, N. L. Diversidade Étnico-Racial, inclusão e equidade na educação brasileira: Desafios, políticas e práticas, 2010.

GUIMARÃES, Selva. Didática e prática de Ensino de História. Papirus Editora. $13^{\circ}$ ed. 2015.

LÜDKE, Menga; ANDRÉ, Marli E.D.A. Pesquisa em educação: abordagens qualitativas. São Paulo: EPU, 1986.

MUNANGA, Kabengele (org). Superando o racismo na escola. $2^{\circ}$ Ed. [Brasília]: Ministério da Educação, Secretaria de Educação Continuada, Alfabetização e Diversidade, 2005.

RIBEIRO, Renilson Costa. Letras negras, páginas brancas: as imagens do negro entre a historiografia e o ensino de história (Brasil, segunda metade do século XX). ETD. Campinas, SP. V. 15, n. 2. P. 281-299, maio/ago. 2013.

SANTOS, Boaventura de Sousa. A Gramática do Tempo: Para uma Nova Cultura Política. São Paulo: Cortez, 2008.

SANTOS, Raquel Amorim dos. [In]visibilidade Negra: representação social de professores acerca das relações raciais no currículo escolar do Ensino Fundamental em Ananindeua (PA). Universidade Federal do Pará, Belém, 2009. Dissertação.

VEIGA, I. P. A. Inovações e Projeto Político pedagógico: uma relação regulatória ou emancipatória? Caderno Cedes. Campinas, v. 23, $\mathrm{n}^{\mathrm{o}}$ 61, p. 267-281, dezembro 2003. Disponível em: http://www.scielo.br/pdf/ccedes/v23n61/a02v2361.pdf. Acesso em: 05 nov. 2018.

\section{FONTES}

BRASIL. Lei $\mathbf{n}^{\mathbf{0}}$ 9.394, de 20 de dezembro de 1996. Estabelece as diretrizes e bases da educação nacional. Diário Oficial da União. Brasília, DF, 23 dez. 1996.

BRASIL. Lei $\mathbf{n}^{\mathbf{0}} \mathbf{1 0 . 6 3 9}$, de 9 de janeiro de 2003. Altera a lei $\mathrm{n}^{\circ}$ 9.394, de 20 de dezembro de 1996, que estabelece as diretrizes e bases da educação nacional, para incluir no currículo oficial da rede de ensino a obrigatoriedade da temática "História e Cultura Afro-Brasileira", e da outras providências. Disponível em: http// www.planalto.gov.br/ccilvil_03/leis/2003/110.639.htm. Acesso em: 15 de nov. 2018. 
Resolução $N^{o}$ 1, de 17 de junho de 2004, do CNE/MEC, que institui Diretrizes Curriculares Nacionais para a Educação das Relações Étnico-Raciais e para o Ensino de História e Cultura Afro-Brasileira e Africana. Diário Oficial [da] República Federativa do Brasil, Poder Executivo, Brasília, DF, 19 mai. 2004b.

Secretaria de Educação Continuada, Alfabetização e Diversidade. Orientações e Ações para a Educação das Relações Étnico-Raciais. Brasília: SECAD, 2006.

CONSELHO NACIONAL DE EDUCAÇÃO. Parecer CEN/CES 492/2001.

UNIVERSIDADE FEDERAL DO PARÁ. Projeto Político Pedagógico do Curso de História-Licenciatura, Campus Bragança. 2012. Disponível em: Https://www.campusbragança.ufpa/index.php/curso-de-historia. Acesso em: 10 nov. 2018.

Recebido em 23.02.2019

Aprovado em 03.04.2019 